\author{
Arie van Steensel
}

\title{
Middeleeuwse kastelen in het Nederlandse stedelijke landschap
}

Kastelen staan doorgaans op het platteland. Niettemin hebben ze soms een prominente plaats in of nabij de stad. Deze bijdrage gaat in op de vraag van welke betekenis de bouw van kastelen door vorsten en edelen was voor de vorming van steden in de middeleeuwse Nederlanden; daarnaast komt de invloed van de relatie tussen stad en kasteel op de ontwikkeling van de stedelijke morfologie kort aan de orde. Sommige van deze middeleeuwse kastelen leven voort in de hedendaagse stedelijke ruimte, waardoor ze behoren tot het levend verleden.

De oudste versterkte middeleeuwse nederzettingen in de Nederlanden, de zogenaamde ringwalburchten, zijn aangelegd in de periode waarin de inwoners zich probeerden te beschermen tegen de invallen van de Vikingen. De sporen van deze ringwalburchten zijn vandaag de dag nog te vinden in bijvoorbeeld Zeeland (Burgh) en Gelderland (Hunneschans). ${ }^{1}$ In de zuidelijke Nederlanden dateren de oudste kastelen en steden uit de periode van de Karolingische tijd tot de elfde eeuw, maar in de Noordelijke Nederlanden kwamen de processen van 'incastellamento' en verstedelijking pas later op gang. ${ }^{2}$ Dit roept de vraag op welk verband er was tussen beide ontwikkelingen. In hoeverre stimuleerden kastelen de ontwikkeling van stedelijke gemeenschappen? Welke invloed had de ligging van kastelen in of nabij de stad op de inrichting van de stedelijke ruimte? Hoe ontwikkelden de politieke, militaire en economische relaties tussen kasteel en stad in de periode tot het einde van de zestiende eeuw? Na een beknopte schets van historische verspreiding van kastelen en steden volgt in deze bijdrage een korte analyse van de invloed van kastelen op de stedelijke morfologie en de stedelijke samenleving in de middeleeuwse Nederlanden. 


\section{Van Steensel}

\section{Een zestiende-eeuwse stedenatlas}

De stedenatlas van de zestiende-eeuwse cartograaf Jacob van Deventer biedt een goed uitgangspunt voor het in kaart brengen van kastelen die in of nabij steden stonden in de laatmiddeleeuwse Nederlanden. Als specialist in het vervaardigen van gedetailleerde stadsplattegronden produceerde hij deze driedelige atlas tussen 1545 en 1575 voor de Spaanse koning Filips II. Twee delen zijn bewaard gebleven en recentelijk integraal en met een uitgebreide toelichting in druk verschenen, samen met de bekende losse stadsplattegronden die mogelijk in het verloren eerste deel waren opgenomen. ${ }^{3}$ Toch ontbreken er van sommige steden plattegronden, waarvan Antwerpen, Maastricht en Namen opvallende voorbeelden zijn. Deze zestiende-eeuwse atlas biedt niettemin een unieke momentopname van de kastelen in het stedelijke landschap van de laatmiddeleeuwse Nederlanden, al beperkte Van Deventer zich tot de gebieden die onder het gezag van de Habsburgse vorsten vielen.

Middeleeuwse kastelen waren er in verschillende vormen en maten, maar ze onderscheidden zich van andere bouwwerken door hun bewoonbaarheid en verdedigbaarheid. ${ }^{4}$ Met dit praktische criterium kan doorgaans vastgesteld worden of een bouwwerk op de plattegronden aangemerkt moet worden als kasteel. In een aantal gevallen is er echter een specifieke afweging gemaakt. Ten eerste waren verschillende kastelen in de zestiende eeuw reeds ingrijpend verbouwd of geheel afgebroken. Het door Jan van der Lede, rond het midden van de dertiende eeuw, gebouwde kasteel bij Schoonhoven brandde bijvoorbeeld in 1518 af, terwijl het wel van invloed op de stedelijke ontwikkeling was geweest. ${ }^{5}$ Ten tweede zijn enkele kastelen niet duidelijk op de plattegronden herkenbaar. Een voorbeeld is de woontoren Oostende in Goes: oorspronkelijk een mottekasteel, maar in de dertiende eeuw versteend en in de vijftiende eeuw in gebruik als baljuwshuis. ${ }^{6}$ Tot slot zijn er verschillende bouwwerken minder goed te typeren. Een voorbeeld is de onbewoonde burcht van Leiden, een elfde-eeuws mottekasteel dat strategisch gelegen was op het punt waar de Oude en de Nieuwe Rijn samenvloeiden. ${ }^{7}$ Ook de meegetelde blokhuizen of dwangburchten met een militair karakter, die in de eerste helft van de zestiende eeuw opgetrokken werden, waren strikt genomen misschien geen kastelen. In 1500 liet hertog Albrecht van Saksen een dergelijk artilleriefort bouwen in Harlingen en Van Deventer tekende ook blokhuizen in op de kaarten van Stavoren en Leeuwarden..$^{8}$ Ook de zestiende-eeuwse citadellen, zoals het Spanjaardenkasteel dat Karel V in 
1540 in Gent (zie afbeelding 1; aan de oostkant van de stad) liet optrekken, zijn op grond van hun typologische verwantschap met het middeleeuwse kasteel meegeteld. ${ }^{9}$

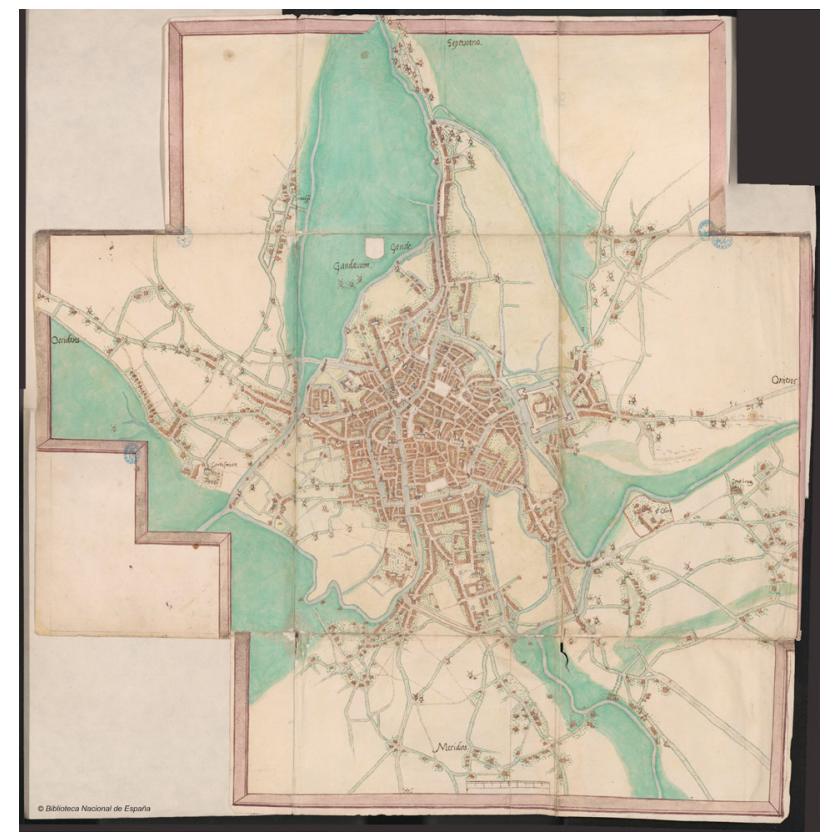

Afbeelding 1: Kaart van Gent.

Het adelijke en vorstelijk stadskasteel of -paleis (hôtel of palais) is daarentegen buiten beschouwing gelaten. De Utrechtse stadskastelen zijn een voorbeeld, al stonden deze versterkte, maar onverdedigbare woningen vooral in de zuidelijke Nederlanden. Te denken valt aan het paleis van de heren van Gruuthuse in Brugge of het paleis van Nassau op de Koudenberg te Brussel, niet ver van het paleis van de Brabantse hertogen. Deze hoven hadden evenwel geen verdedigende functie meer. Tot slot zijn versterkte nederzettingen evenmin opgenomen in de analyse. Het betreft dan bourgs castraux uit de centrale middeleeuwen, maar vooral zestiende-eeuwse vestingstadjes, zoals Mariembourg of Hesdin. In de periode dat Van Deventer zijn stedenatlas vervaardigde, werden nieuwe fortificaties aangelegd om de zwaardere artillerie te kunnen weerstaan. 


\section{Van Steensel}

\section{De verspreiding van kastelen}

De grenzen van de Habsburgse Nederlanden liepen anders dan de huidige grenzen van Nederland en België, vandaar dat Van Deventer ook plattegronden tekende van steden die nu bijvoorbeeld in Frankrijk of Duitsland liggen. In totaal telt de atlas plattegronden van 226 plaatsen, al waren deze lang niet allemaal steden in politiek-juridische of sociaaleconomische zin. Reinout Rutte en Bram Vannieuwenhuyze spreken dan ook van 'mislukte steden of twijfelgevallen', zoals de plaatsen Genemuiden, Chiny of Lillers, waar een kasteel of blokhuis stond. ${ }^{10}$

Op 137 stadsplattegronden staan in totaal 179 kastelen weergegeven, dus bij 61 procent van de getekende steden staat een of meerdere kastelen afgebeeld. In tabel 1 staat de chronologische verspreiding van deze kastelen weergegeven. De eerste bouwfase van kastelen is overigens vaak alleen globaal te dateren. Uit de gegevens die ontleend zijn aan de uitgave van Rutte en Vannieuwenhuyze, blijkt dat de oudste kastelen terug te vinden zijn

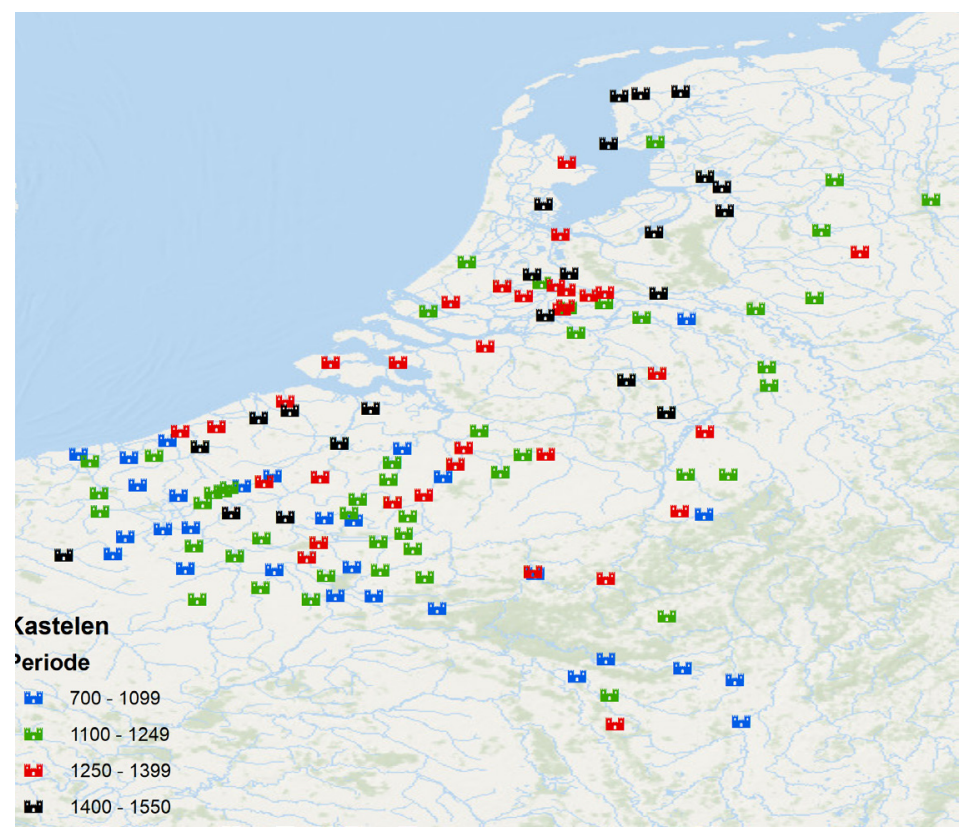

Kaart 1: Kastelen in en nabij steden in de laatmiddeleeuwse Nederlanden. 
in de zuidelijke Nederlanden, met name in het grensgebied met Frankrijk. Het patroon van de verspreiding van het zuiden naar het noorden is goed af te lezen van kaart 1; daarnaast valt op dat veel kastelen in de buurt van

\begin{tabular}{|l|l|l|l|l|l|l|}
\hline Regio & Voor 1099 & $1100-1249$ & $1250-1399$ & $1400-1550$ & $\begin{array}{l}\text { Aantal } \\
\text { kastelen } \\
\text { in/bij stad }\end{array}$ & $\begin{array}{l}\text { Totaal } \\
\text { aantal } \\
\text { steden }\end{array}$ \\
\hline $\begin{array}{l}\text { Brabant, } \\
\text { Weert, } \\
\text { Mechelen en } \\
\text { Aarschot }\end{array}$ & 4 & 9 & 6 & 2 & 21 & 19 \\
\hline $\begin{array}{l}\text { Landen van } \\
\text { Overmaas, } \\
\text { Limburg, } \\
\text { Luxemburg, } \\
\text { Namen en } \\
\text { Mariënburg }\end{array}$ & 7 & 5 & 4 & - & 16 & 19 \\
\hline Henegouwen & 9 & 15 & 4 & - & 28 & 24 \\
\hline $\begin{array}{l}\text { Cambrésis en } \\
\text { Artesië }\end{array}$ & 10 & 4 & - & 1 & 15 & 12 \\
\hline $\begin{array}{l}\text { Vlaanderen en } \\
\text { Tournai }\end{array}$ & 23 & 14 & 6 & 7 & 50 & 43 \\
\hline $\begin{array}{l}\text { Holland en } \\
\text { Zeeland }\end{array}$ & - & 6 & 13 & 3 & 22 & 49 \\
\hline $\begin{array}{l}\text { Friesland, } \\
\text { Groningen en } \\
\text { Coevorden }\end{array}$ & - & 4 & 2 & 3 & 9 & 14 \\
\hline $\begin{array}{l}\text { Sticht Utrecht } \\
\text { en Oversticht }\end{array}$ & & 1 & 1 & 4 & 6 & 21 \\
\hline $\begin{array}{l}\text { Lingen, } \\
\text { Culemborg, } \\
\text { Buren, Gelre en } \\
\text { Zutphen }\end{array}$ & 1 & 5 & 3 & 3 & 12 & 25 \\
\hline Totaal & 54 & 63 & 39 & 23 & 179 & 226 \\
\hline
\end{tabular}

Tabel 1: Verspreiding van kastelen in en nabij steden in de Nederlanden, c. 700-1550.

belangrijke waterwegen waren gebouwd, bijvoorbeeld in het Maasgebied en langs de grote rivieren in het midden van de Noordelijke Nederlanden.

De oudste kastelen stonden vaak in of nabij nederzettingen uit de Romeinse en Karolingische tijd die onder de grote rivieren lagen. De 


\section{Van Steensel}

oorsprong van Arras gaat bijvoorbeeld terug op een Romeins castrum, terwijl het Valkhof in Nijmegen gebouwd is als burcht- en paleiscomplex van Karel de Grote. De kastelen uit de periode van de elfde tot halverwege de dertiende eeuw waren doorgaans residenties van regionale vorsten, donjons, en mottekastelen gebouwd door lokale heren. In de latere periode betrof het doorgaans waterkastelen, die in omvang varieerden van veelhoekige kastelen tot compacte vierkante of ronde woontorens, afhankelijk van de financiële middelen van de eigenaar. Deze kastelen, zoals ze op Van Deventers plattegronden afgebeeld staan, kenden vaak een lange bouwgeschiedenis met verschillende fases van bouw, renovatie of (gedeeltelijke) afbraak. Op het einde van de middeleeuwen kregen sommige nieuwe kastelen weer een sterkere militaire functie als blokhuis of artilleriefort.

\begin{tabular}{|c|c|c|c|c|c|}
\hline Regio & $\begin{array}{l}\text { Kasteel van } \\
\text { lokale heer }\end{array}$ & \begin{tabular}{|l} 
Lokale \\
stadsheer
\end{tabular} & $\begin{array}{l}\text { Stad ouder } \\
\text { dan kasteel }\end{array}$ & $\begin{array}{l}\text { Kasteel } \\
\text { buiten de } \\
\text { stad }\end{array}$ & $\begin{array}{l}\text { Totaal } \\
\text { aantal } \\
\text { kastelen }\end{array}$ \\
\hline $\begin{array}{l}\text { Brabant, Weert, } \\
\text { Mechelen en } \\
\text { Aarschot }\end{array}$ & 14 & 5 & 5 & 10 & 21 \\
\hline $\begin{array}{l}\text { Landen van } \\
\text { Overmaas, } \\
\text { Limburg, } \\
\text { Luxemburg, } \\
\text { Namen en } \\
\text { Mariëeburg }\end{array}$ & 2 & 7 & 1 & 7 & 16 \\
\hline Henegouwen & 13 & 6 & 6 & 2 & 28 \\
\hline $\begin{array}{l}\text { Cambrésis en } \\
\text { Artesië }\end{array}$ & 3 & 2 & 3 & 1 & 15 \\
\hline $\begin{array}{l}\text { Vlaanderen en } \\
\text { Tournai }\end{array}$ & 17 & 4 & 12 & 12 & 50 \\
\hline $\begin{array}{l}\text { Holland en } \\
\text { Zeeland }\end{array}$ & 16 & 12 & 4 & 9 & 22 \\
\hline $\begin{array}{l}\text { Friesland, } \\
\text { Groningen en } \\
\text { Coevorden }\end{array}$ & 2 & 1 & 3 & - & 9 \\
\hline $\begin{array}{l}\text { Sticht Utrecht en } \\
\text { Oxersticht }\end{array}$ & 2 & 4 & 3 & 3 & 6 \\
\hline $\begin{array}{l}\text { Lingen, } \\
\text { Culemborg, } \\
\text { Buren, Gelre en } \\
\text { Zutphen }\end{array}$ & 5 & 5 & 4 & 6 & 12 \\
\hline Totaal & 74 & 46 & 41 & 50 & 179 \\
\hline
\end{tabular}

Tabel 2: Relaties tussen kasteel en stad in de laatmiddeleeuwse Nederlanden. 
Regionale vorsten waren de belangrijkste kastelenbouwers, want lokale adellijke heren waren slechts bij 41 procent van de geïdentificeerde kastelen (tabel 2, kolom 2) verantwoordelijk voor de bouw daarvan. Vorsten hadden belang bij het bouwen van kastelen om zo hun grip over een territorium of stad te versterken, zoals de Henegouwse graaf Boudewijn IV (1120-1171) en de Hollandse graaf Floris V (1256-1296), die een waar beleid van stad- en kasteelstichtingen voerden. ${ }^{11}$ Lokale heren hadden verschillende motieven om een kasteel te bouwen: het diende als woning en machtscentrum, bood fysieke bescherming tijdens conflicten en gaf uitdrukking aan de hoge sociale status van de eigenaar. ${ }^{12}$ In de late middeleeuwen was het bezitten van een kasteel een belangrijk symbolisch teken van adellijke status. Om die reden liet bijvoorbeeld de Bourgondische geadelde hoge ambtenaar Pieter Bladelin rond het midden van vijftiende eeuw een kasteel en een stadje aanleggen in Middelburg (Vlaanderen), een heerlijkheid die hij kort daarvoor had verkregen. ${ }^{13}$

\section{Verkasteling en verstedelijking}

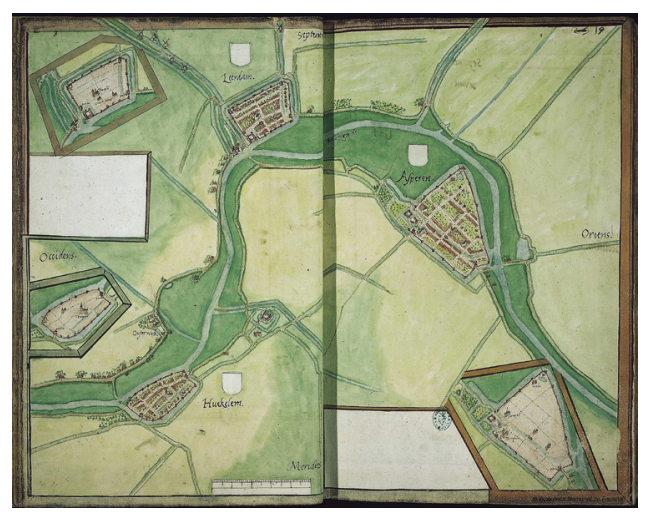

Afbeelding 2: Asperen, Heukelum en Leerdam

Het merendeel van de kastelen stond op het platteland, maar rond veel kastelen ontstonden stedelijke nederzettingen. Dit gebeurde vanaf de tiende eeuw, bijvoorbeeld in steden als Gent, Oudenaarde en Valenciennes, waar handel en nijverheid pas in de elfde eeuw duidelijk een impuls gaven aan de stadwording van nederzettingen nabij kastelen. ${ }^{14}$ Evenals abdijen waren hoven van vorsten en lokale heren belangrijke centra in de domaniale economie, waar consumptie, handel en productie zich concentreerden. ${ }^{15}$ De bouw van kastelen was daarom niet alleen ingegeven door militaire of politieke motieven, maar ook door economische overwegingen. Heren stimuleerden uit eigen belang vaak commerciële activiteiten rond hun kasteel. In meer dan driekwart van de gevallen stond er al een kasteel voordat er sprake was van stadsvorming en 47 steden (twintig procent van de 226 steden) ontvingen 


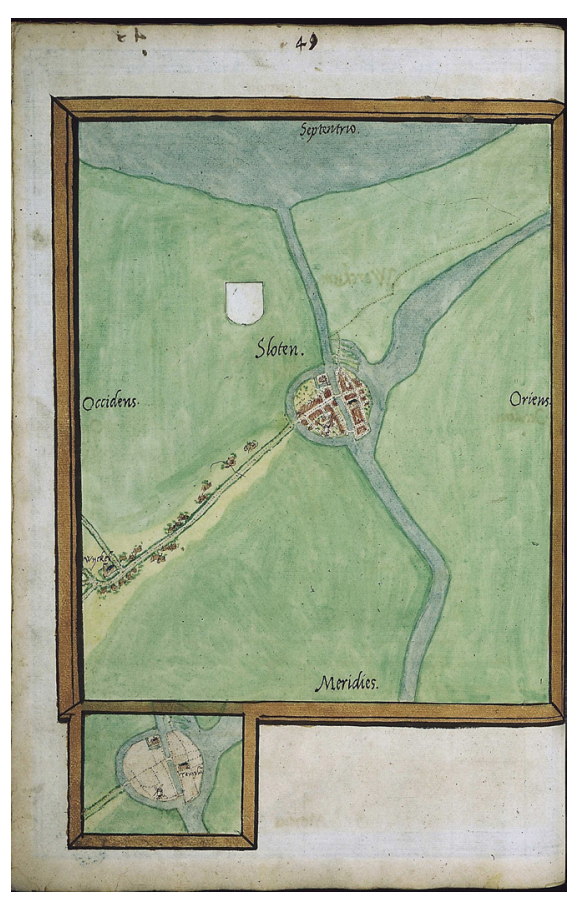

Afbeelding 3: 's-Heerenberg en Sloten.

stadsrechten van een lokale heer. Vorsten verleenden stadsrechten aan de overige steden, al gebeurde dit doorgaans aan nederzettingen die reeds een stedelijk karakter in ruimtelijke en sociaal-economische zin hadden.

Het patroon van verstedelijking in de middeleeuwse Nederlanden volgde in grote lijnen het patroon van verkasteling. Het Maasland blijft enigszins buiten beeld in Van Deventers atlas, maar dit was een kernregio waar tussen de achtste en elfde eeuw de eerste steden ontstonden. In dezelfde periode ontwikkelde zich een tweede kernregio in Artesië, Vlaanderen en Brabant, voornamelijk in het Scheldegebied van Arras tot Antwerpen. Het ontstaan van steden in de noordelijke gebieden, met name langs de IJssel en de Noordzeekust, kwam pas in deloop van de dertiende eeuw op gang. ${ }^{16}$ Sommige regionale vorsten ontwikkelden een actieve rol in de stichting van steden, zoals de Vlaamse graaf Filips van de Elzas (1168-1179) en de Gelderse graven Gerard III (1185-1229) en Otto II (1229-1271). ${ }^{17}$ Het slagen van dergelijke stichtingen was echter niet alleen afhankelijk van machtspolitiek, want vaak bleven deze plaatsen in economisch en demografisch opzicht klein. Hetzelfde gold voor steden die gesticht waren door lokale kasteelheren en voor stadsvorming rond kastelen in algemene zin: als deze geen gunstige geografische ligging hadden, concurrentie ondervonden van andere steden, relatief laat gesticht werden, of geen duidelijke functie vervulden in een economisch systeem, dan bleven groei en bloei uit.

In de Noordelijke Nederlanden lag het aantal steden dat van een lokale heer rechten kreeg gemiddeld iets hoger, maar vaak waren dit relatief jonge steden. Het Zeeuwse stadje Veere verkreeg bijvoorbeeld in 1355 stadsrechten van zijn heer, Wolfert van Borssele, die op het nabijgelegen 
kasteel Zandenburg woonde, en profiteerde van de aanwezigheid van buitenlandse handelaren en zijn ligging in het Scheldegebied. ${ }^{18}$ In de Vijfheerenlanden, op de grens tussen Gelre en Holland, concurreerden verschillende machtige adellijke geslachten met elkaar in de veertiende eeuw. Dit leidde tot de stichting van steden als Buren en Culemborg en de dicht op elkaar liggende stadjes Asperen, Heukelum en Leerdam (zie afbeelding 2), die echter demografisch en economisch niet tot echte bloei kwamen. ${ }^{19}$ De investeringen van lokale heren waren gericht op het vergroten van hun macht, inkomsten en status, maar het rendement bleef op de lange termijn vaak beperkt. Ook stadjes als 's-Heerenberg (graven van Bergh) in Gelre en Sloten (geslacht Harinxma; zie afbeelding 3) in Friesland hadden door hun ligging onvoldoende economisch potentieel en aantrekkingskracht op migranten, waardoor hun stedelijke ontwikkeling niet van de grond kwam. De aanwezigheid van een kasteel was geen voldoende voorwaarde voor succesvolle stadswording of stichting.

Kasteel in/en de stad

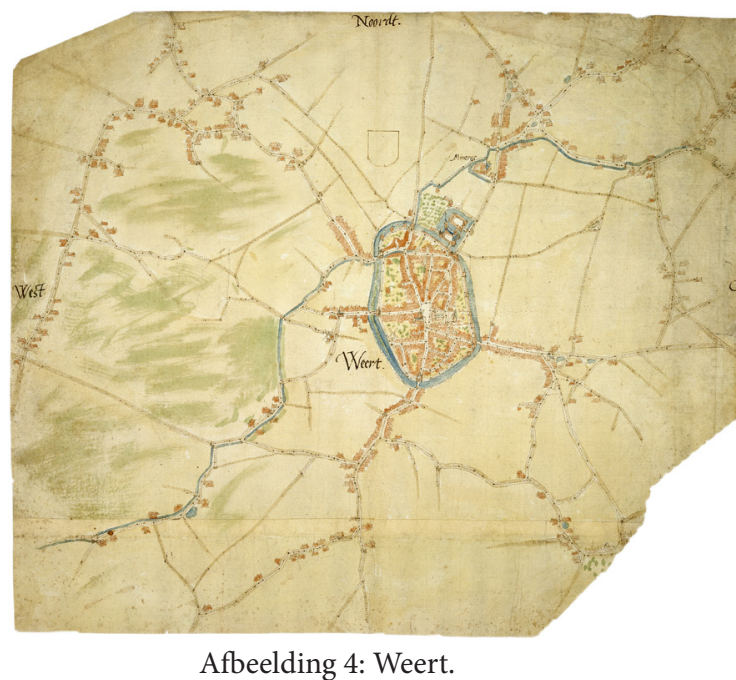

Van de 179 kastelen lagen er vijftig verder van de stad af (zie tabel 2); de overige kastelen stonden binnen de stadsmuren of grensden daar direct aan. Soms vormde een nederzetting zich direct rond het kasteel, maar het kwam ook voor dat een kasteel bij latere stadsuitbreidingen daarbinnen kwam te liggen of werd herbouwd. Vanaf de dertiende eeuw droegen steden doorgaans zelf de verantwoordelijkheid om defensieve versterkingen aan te leggen en te onderhouden, tenzij de vorst direct belang had bij een versterkte vesting. ${ }^{20}$ Het waren in deze periode vooral lokale stadsheren die nieuwe kastelen bouwden, vaak als onderdeel van de stedelijke ommuring. 


\section{Van Steensel}

Jan van Beieren liet bijvoorbeeld tussen 1407 en 1415 de stad Woerden versterken en een nieuw kasteel optrekken; de heren van Horne bouwden in 1455 een burcht, de Nyenborgh, aan de noordkant van de stad Weert (zie afbeelding 4). ${ }^{21}$

Kastelen stonden doorgaans op strategische plaatsen op een (kunstmatige) verhoging of langs waterwegen om routes over het land en het water te controleren. De oudste steden vormden zich als nederzettingen rond deze kastelen, al was de bouw van kerken, markten en havens waarschijnlijk een factor die meer dan het kasteel een stempel drukte op de ontwikkeling van de stedelijke ruimte. ${ }^{22}$ De oudere steden die geleidelijk gegroeid waren, hadden ook een meer geëvolueerd stratenplan dan de ontworpen nieuwe steden van de late middeleeuwen. Over het algemeen stonden kastelen gezien hun functie aan de rand van de stad, waardoor ze geen deel uitmaakten van de kern van de stedelijke bebouwing. Dit sloot overigens niet uit dat kastelen belangrijke politieke, sociale en economische functies voor de stad vervulden.

Kastelen waren in de eerste plaats een machtssymbool, maar in praktische zin waren ze gericht op het verdedigen of beheersen van een stad. Dit laatste impliceert dat de relatie tussen de kasteelheer en de stedelijke gemeenschap niet per definitie aimabel was. ${ }^{23}$ Hoewel kasteelheren de ontwikkeling van de stedelijke economie stimuleerden - denk ook aan de consumptie aan het hof van de kasteelheer - en politieke voorrechten verleenden aan de stedelijke gemeenschappen, was het kasteel ook een teken van de onderworpenheid van stad aan het gezag van hun heer, of dat nu een regionale vorst of een lokale edele was. Als de wederkerigheid onder druk kwam te staan, dan leidde dat tot spanningen. Conflicten tussen vorsten en steden zijn goed onderzocht, maar over spanningen tussen lokale stadsheren Den stedelingen is minder bekend. Een van de weinige bekende voorbeelden is dat van Leerdam. In 1407 erkende deze stad de graaf van Holland als nieuwe heer, maar de oorspronkelijke stadsheer, de edelman Jan van Arkel, veroverde zijn stad spoedig daarna terug op zijn Hollandse tegenstander. ${ }^{24}$

Veel middeleeuwse kastelen zijn inmiddels verdwenen, maar in verscheidene Belgische en Nederlandse steden zijn ze nog te bezichtigen, soms slechts in gerestaureerde vorm of als ruïne, zoals in Gent of Culemborg. Achter deze versteende herinnering aan de middeleeuwen schuilen complexe processen van verkasteling en verstedelijking met regionaal gevarieerde uitkomsten, die van grote invloed zijn geweest op de geschiedenis van de Nederlanden. Stad en kasteel waren in het middeleeuwse politieke en economische landschap ook niet van elkaar gescheiden, maar juist met elkaar 
verknoopt. Deze knoop kan vanuit verschillende invalshoeken verder worden ontrafeld. De vroege economische relaties tussen kastelen en nabijgelegen nederzettingen in de Zuidelijke Nederlanden suggereert een wisselwerking tussen beide processen, daarom kan de verspreiding van kastelen eerder als katalysator dan als oorzaak van vroege stadswording beschouwd worden. In de Noordelijke Nederlanden kwam de verstedelijking later op gang en was de rol van kasteelbouw daarin gering. Bovendien is er nog relatief weinig onderzoek verricht naar invloed van kastelen op de stedelijke morfologie en de relaties tussen stadsheer en stedelijke gemeenschap. Tot slot problematiseert het verspreidingspatroon van kastelen de tegenstelling die in de middeleeuwse Nederlanden zou zijn ontstaan tussen de relatief dichtbevolkte, verstedelijkte en gecommercialiseerde kustgewesten en de meer rurale landgewesten met een lagere bevolkingsdichtheid.

\section{Noten}

1. R. M. van Heeringen, P.A. Henderikx en J. Buurman, red., Vroeg-Middeleeuwse ringwalburgen in Zeeland (Goes: De Koperen Tuin, 1995).

2. A. E. Verhulst, The rise of cities in North-West Europe (Cambridge: Cambridge University Press, 1999), 161.

3. R. Rutte en B. Vannieuwenhuyze, Stedenatlas Jacob van Deventer: 226 stadsplattegronden uit 1545-1575. Schakels tussen verleden en heden (Bussum: Uitgeverij THOTH, 2018).

4. H. L. Janssen, “Tussen woning en versterking. Het kasteel in de Middeleeuwen," in 1000 jaar kastelen in Nederland. Functie en vorm door de eeuwen heen, red. H.L. Janssen, J.M.M. Kylstra-Wielinga en B. Olde Meierink (Utrecht: Matrijs, 1996), 15-19.

5. T. Hermans en M. Brongers, "Het onvoltooide kasteel van Schoonhoven," Castellogica 1 (1983): 32-38.

6. J. P. van den Broecke, Middeleeuwse kastelen van Zeeland. Bijzonderheden over verdwenen burchten en ridderhofsteden (Delft: Elmar, 1978), 72-75.

7. E.T. van der Vlist, De burcht van Leiden (Leiden: Primavera Pers, 2001).

8. J. A. van der Hoeve, "Het blokhuis te Harlingen, Weeshuisstraat 1/3", Bulletin KNOB 102 (2003): 13-19.

9. B. de Rijk, "Tussen vesting en residentie. De zestiende eeuw," in 1000 jaar kastelen in Nederland. Functie en vorm door de eeuwen heen, red. H. L. Janssen, J. M. M. Kylstra-Wielinga en B. Olde Meierink (Utrecht: Matrijs, 1996), 112-139.

10. Rutte and Vannieuwenhuyze, Stedenatlas Jacob van Deventer, 495.

11. R. Deprez, "La politique castrale dans la principauté épiscopale de Liège du Xe au XIVe siècle," Le Moyen Âge 65 (1959): 501-538; M.-A. Arnould et al., red., Châteaux, chevaliers en Hainaut au Moyen Âge (Bruxelles: Crédit communal, 1995); J. G. N. Renaud, "Graaf Floris V als burchtenbouwer," Berichten van de Rijksdienst voor het 


\section{Van Steensel}

Oudheidkundig Bodemonderzoek 8 (1957-1958): 159-171.

12. F. Doperé, "Le château médiéval comme expression du pouvoir seigneurial dans les anciens Pays-Bas méridionaux," in Lieu de pouvoir, lieu de gestion: le château aux XIIIe-XVIe siècles: maîtres, terres et sujets, red. J.-M. Cauchies en J. Guisset (Turnhout: Brepols, 2011), 111-132.

13. W. De Clercq, J. Dumolyn, en J. Haemers, "Vivre noblement': Material culture and elite identity in late medieval Flanders," Journal of Interdisciplinary History 38, no. 1 (2007): 1-31.

14. O. H. Creighton, Castles and landscapes: Power, community and fortification in medieval England (London: Equinox Publishing, 2005), 151-63; Verhulst, The rise of cities, 66-69.

15. B. J. P. van Bavel, Manors and markets: Economy and society in the Low Countries, 500-1600 (Oxford: Oxford University Press, 2010), 64-65, 72, 108, 154-155.

16. W. P. Blockmans, Metropolen aan de Noordzee: de geschiedenis van Nederland, 1100-1560 (Amsterdam: Bert Bakker, 2010), 21-22. Zie voor een typering van de verschillende generaties steden: R. Rutte, "Stadslandschappen. Een overzicht van de stadswording in Nederland van de elfde tot de vijftiende eeuw," in Stadswording in de Nederlanden. Op zoek naar overzicht, red. R. Rutte en H. van Engen (Hilversum: Verloren, 2005), 143-170; Rutte and Vannieuwenhuyze, Stedenatlas Jacob van Deventer, 475-495.

17. R. Rutte, Stedenpolitiek en stadsplanning in de Lage Landen (12de-13de eeuw) (Zwolle: Walburg Pers, 2002), 54.

18. P. Blom e.a., Borsele, Bourgondië, Oranje: Heren en markiezen van Veere en Vlissingen, 1400-1700 (Hilversum: Verloren, 2009).

19. R. J. Rutte, "Falen of slagen. Motieven bij laatmiddeleeuwse stadsstichtingen," Historisch Geografisch Tijdschrift 18 (2000): 1-11.

20. M. De Waha, "De la collaboration à la confrontation. Enceintes urbaines et châteaux princiers dans les villes des anciens Pays-Bas," in Le château et la ville. Conjonction, opposition, juxtaposition (XIe-XVIIIe siècle), red. G. Blieck et al. (Paris: Éditions du CTHS, 2002), 178.

21. Janssen, "Tussen woning en versterking," 74-76.

22. J. De Meulemeester, "La fortification de terre et son influence sur le développement urbain de quelques villes des Pays-Bas méridionaux," Revue du Nord 74, no. 296 (1992): 13-28.

23. Ph. Contamine, "Ville et château au Moyen Âge. Introduction historique," in Le château et la ville. Conjonction, opposition, juxtaposition (XIe-XVIIIe siècle), red. G. Blieck et al. (Parijs: Éditions du CTHS, 2002), 9-20.

24 . A. Janse, Verkochte vrijheid. Het Leerdamse stadsrecht van 1407 (Hilversum: Verloren, 2007).

\section{Afbeeldingen}

Bron afbeelding $1 \mathrm{t} / \mathrm{m}$ 4: Biblioteca Nacional de España, Madrid, Manuscritos, Res. 200 en 207; Regionaal Historisch Centrum Limburg, Maastricht, RAL_K_107_1_01.

\section{2}

